\title{
THE EFFECTS OF TWENTY DEGREE HEAD-UP TILT UPON THE CEREBRAL CIRCULATION OF PATIENTS WITH ARTERIAL HYPERTENSION BEFORE AND AFTER SYMPATHECTOMY ${ }^{1}$
}

\author{
By JOSEPH H. HAFKENSCHIEL, CHARLES W. CRUMPTON, ${ }^{2}$ HENRY A. \\ SHENKIN, JOHN H. MOYER, 3 HAROLD A. ZINTEL, HERBERT \\ WENDEL, ${ }^{4}$ AND WILLIAM A. JEFFERS, WITH THE TECH NICAL \\ ASSISTANCE OF SALLY CONLIN HARNED, NELLY \\ J. KEFFER, AND GERALDINE CROFT \\ (From the Edward B. Robinette Foundation, Medical Clinic, Hospital of the University of Penn- \\ sylvania, the Graduate Hospital, the Department of Pharmacology, and the Harrison \\ Department of Research Surgery of the School of Medicine of the University \\ of Pennsylvania, Philadelphia, Pa.)
}

(Submitted for publication October 5, 1950 ; accepted May 23, 1951)

The present study was undertaken in order to measure the effect of a slight elevation of the head and shoulders upon the cerebral circulation of hypertensive patients following sympathectomy. Twenty degree tilt was chosen because it could be tolerated for 20 minutes, as early as two weeks after the Smithwick sympathectomy.

Shenkin and coworkers in 1948 reported that $20^{\circ}$ head-up tilt did not alter the cerebral blood flow, cerebral oxygen consumption, and oxygen content of the internal jugular blood in five normal subjects (1). They also reported that, following thoracolumbar sympathectomy, cerebral oxygen uptake and blood flow in hypertensive patients while in the supine position did not differ from the preoperative level (2).

We have measured mean arterial pressure, blood flow, and oxygen uptake of the brain, before and after tilt in two groups of patients: (a) 15 patients who had been subjected to bilateral thoracolumbar (D6-L3) sympathectomy, and (b) 18 patients with essential hypertension.

\section{METHODS}

Patients with essential hypertension were selected from the medical and surgical wards of the Hospital of the

1 This study was supported in part by research grants from the National Heart Institute, U. S. Public Health Service, the Life Insurance Medical Research Fund, Sandoz Pharmaceuticals, Irwin, Neisler and Company, and the Squibb Institute for Medical Research.

2 Present address: University of Wisconsin, School of Medicine, Madison, Wis.

3 Present address: Department of Medicine, Baylor University College of Medicine, Houston, Texas.

4 Present address: Berlin-Zehlendorf, Irmgardstr., 45, U. S. Sector, Berlin, Germany.
University of Pennsylvania and the Graduate Hospital of the University of Pennsylvania. Preoperatively all had moderate to marked hypertension with retinopathy ${ }^{5}$ grades II to IV (3), fluoroscopic and electrocardiographic evidences of left ventricular hypertrophy, and moderate impairment of renal function as measured by PSP excretion and urea clearance tests. At the time of the tilt study no patient showed either elevation of the blood urea nitrogen above $20 \mathrm{mgm}$. \% or signs of congestive heart failure.

The patients studied after sympathectomy were selected at random without regard to the severity of the postoperative postural hypotension. All were ambulatory. Sympathectomies had been completed from two weeks to seven years prior to testing. Ten of the 17 tilts following sympathectomy were made in the 12 months. immediately after operation, and of these ten, eight were studied within six months after operation.

Control measurements of cerebral blood flow, oxygen consumption, and mean femoral arterial pressure (4) were made in the supine position in a room kept as cool as was consistent with the patient's comfort. Accurate control of the environmental temperature was not possible. The patient was then tilted to a $20^{\circ}$ head-up position. After three minutes in this position, simultaneously drawn samples of blood from the femoral artery and the internal jugular vein were obtained for analyses of oxygen and carbon dioxide content and blood $\mathrm{pH}$ as previously reported (5). When the patient had been in the head-up position for 20 minutes the second cerebral blood flow and oxygen consumption measurement was made. The pressure in the femoral artery during tilt and the vertical distance from the position of the needle to the level of the patients' eyes were recorded. The cerebral arterial pressure was then calculated as reported by Scheinberg and Stead (6). The jugular venous pressure was then subtracted from the calculated cerebral arterial pressure to give "effective" cerebral arterial pressure. Ve-

5 These examinations were made by Dr. Irving $\mathrm{H}$. Leopold, Department of Ophthalmology, Hospital of the University of Pennsylvania. 
nous pressure was measured (at the level of the internal jugular bulb) both while in the supine position and at the end of the tilt period while still semi-erect.

\section{RESULTS}

Table I contains the data on each patient. Also included are values previously reported for the normotensives. The percentage change and the significant differences from the supine value in each group are given in Table II. There were no highly significant differences between the mean differences of the three groups in any of the variables.

\section{Mean arterial pressure}

The "effective" cerebral mean arterial pressure was decreased by tilt in both groups of patients.

Eight patients tilted within six months or less after sympathectomy showed a highly significant change only in "effective" cerebral arterial pres-

TABLE I

Effects of $20^{\circ}$ head-up tilt on cerebral circulation and oxygen metabolism

\begin{tabular}{|c|c|c|c|c|c|c|c|c|c|c|c|c|c|c|c|c|}
\hline \multirow[t]{2}{*}{ Patient group } & \multirow{2}{*}{$\begin{array}{l}\text { Retino- } \\
\text { pathy } \\
\text { grade }\end{array}$} & \multicolumn{3}{|c|}{$\begin{array}{l}\text { "Effective" cerebral mean } \\
\text { arterial pressure, } \mathrm{mm} . \mathrm{Hg}\end{array}$} & \multicolumn{3}{|c|}{$\begin{array}{l}\text { Oxygen content } \\
\text { internal jugular } \\
\text { vein, vol. } \%\end{array}$} & \multicolumn{3}{|c|}{$\begin{array}{l}\text { Arteriovenous } \\
\text { oxygen differ- } \\
\text { ence, vol. } \%\end{array}$} & \multicolumn{2}{|c|}{$\begin{array}{c}\text { Cerebral } \\
\text { oxygen up- } \\
\text { take, cc./100 } \\
\text { G./min. }\end{array}$} & \multicolumn{2}{|c|}{$\begin{array}{c}\text { Cerebral } \\
\text { blood flow, } \\
c c . / 100 \\
\text { G./min. }\end{array}$} & \multicolumn{2}{|c|}{$\begin{array}{l}\text { Vascular } \\
\text { resistance }\end{array}$} \\
\hline & & $\mathbf{S}$ & $3^{\prime}$ & $20^{\prime}$ & $\mathbf{S}$ & $3^{\prime}$ & $20^{\prime}$ & $\mathbf{S}$ & $3^{\prime}$ & $20^{\prime}$ & $\mathbf{S}$ & $20^{\prime}$ & $\mathbf{S}$ & $20^{\prime}$ & $\mathrm{S}$ & $20^{\prime}$ \\
\hline 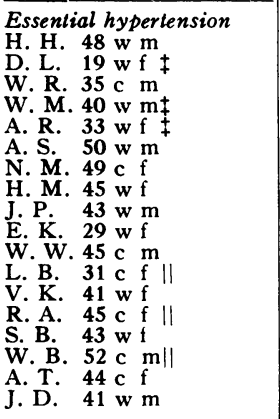 & $\begin{array}{l}\text { III } \\
\text { IV } \\
\text { II } \\
\text { IV } \\
\text { II } \\
\text { III } \\
\text { III } \\
\text { IV } \\
\text { IV } \\
\text { II } \\
\text { II } \\
\text { III } \\
\text { II } \\
\text { II } \\
\text { II } \\
\text { III } \\
\text { III } \\
\text { II }\end{array}$ & $\begin{array}{l}144 \\
141 \\
114(4.9) 8 \\
144(9.2) \\
130 \\
127 \\
147(8.1) \\
192(2.9) \\
151(5.6) \\
129(6.5) \\
151(8.2) \\
149(6.2) \\
151(8.1) \\
149 \\
159 \\
156 \\
151(3.7) \\
147\end{array}$ & $\begin{array}{l}118 \\
128 \\
101 \\
128 \\
\\
\\
113 \\
180 \\
114 \\
110 \\
130 \\
143 \\
139 \\
124 \\
166 \\
132 \\
140\end{array}$ & $\begin{array}{l}116 \\
112 \\
96(4.1) 8 \\
121 \\
126 \\
113 \\
104(3.7) \\
162(2.2) \\
128(5.9) \\
111(5.0) \\
138(8.7) \\
134 \\
134 \\
98 \\
123 \\
111 \\
130(2.9) \\
137\end{array}$ & $\begin{aligned} 9.9 \\
12.0 \\
11.1 \\
12.1 \\
9.7 \\
10.5 \\
10.8 \\
10.0 \\
9.6 \\
12.7 \\
11.9 \\
8.1 \\
10.4 \\
12.4 \\
11.3 \\
8.4 \\
10.4 \\
11.8\end{aligned}$ & $\begin{array}{r} \\
10.5 \\
10.4 \\
8.3 \\
12.3 \\
11.8 \\
7.4 \\
10.6 \\
10.1 \\
9.9 \\
8.7 \\
11.4\end{array}$ & $\begin{aligned} 10.0 \\
11.0 \\
9.8 \\
12.7 \\
9.2 \\
8.9 \\
9.5 \\
9.3 \\
8.5 \\
12.2 \\
10.9 \\
7.5 \\
10.5 \\
11.3 \\
10.2 \\
7.8 \\
9.2 \\
11.4\end{aligned}$ & $\begin{array}{l}4.5 \\
4.7 \\
5.4 \\
5.0 \\
8.8 \\
6.3 \\
5.9 \\
7.2 \\
5.2 \\
5.4 \\
5.7 \\
4.9 \\
7.3 \\
6.0 \\
6.2 \\
4.9 \\
6.3 \\
8.2\end{array}$ & $\begin{array}{l}5.6 \\
6.7 \\
6.4 \\
5.6 \\
6.8 \\
5.3 \\
6.5 \\
\\
6.8 \\
5.3 \\
7.5 \\
7.6\end{array}$ & $\begin{array}{l}4.4 \\
5.6 \\
6.9 \\
5.9 \\
9.9 \\
8.3 \\
6.2 \\
7.5 \\
6.4 \\
5.6 \\
6.4 \\
5.3 \\
7.1 \\
6.3 \\
6.7 \\
5.5 \\
7.6 \\
7.9\end{array}$ & $\begin{array}{l}3.5 \\
3.3 \\
3.1 \\
3.1 \\
4.0 \\
3.1 \\
2.9 \\
3.3 \\
2.3 \\
5.0 \\
4.0 \\
4.5 \\
4.7 \\
4.1 \\
3.6 \\
3.3 \\
2.6 \\
2.7\end{array}$ & $\begin{array}{l}3.2 \\
4.0 \\
3.6 \\
3.7 \\
4.1 \\
3.7 \\
3.7 \\
3.3 \\
2.9 \\
5.1 \\
4.2 \\
3.6 \\
4.7 \\
4.5 \\
3.8 \\
3.4 \\
3.3 \\
2.8\end{array}$ & $\begin{array}{l}77 \\
70 \\
58 \\
62 \\
45 \\
49 \\
49 \\
47 \\
48 \\
93 \\
70 \\
91 \\
64 \\
68 \\
58 \\
67 \\
42 \\
33\end{array}$ & $\begin{array}{l}73 \\
71 \\
52 \\
63 \\
41 \\
45 \\
60 \\
44 \\
45 \\
91 \\
65 \\
68 \\
66 \\
72 \\
56 \\
61 \\
43 \\
36\end{array}$ & $\begin{array}{l}1.9 \\
2.0 \\
2.0 \\
2.3 \\
2.9 \\
2.6 \\
2.8 \\
4.1 \\
3.1 \\
1.4 \\
2.2 \\
1.6 \\
2.4 \\
2.2 \\
2.7 \\
2.3 \\
3.6 \\
4.5\end{array}$ & $\begin{array}{l}1.6 \\
1.6 \\
1.8 \\
1.9 \\
3.1 \\
2.5 \\
1.7 \\
3.7 \\
2.8 \\
1.2 \\
2.1 \\
2.0 \\
2.0 \\
1.4 \\
2.2 \\
1.8 \\
3.0 \\
3.8\end{array}$ \\
\hline Mean & & $146(5.7)$ & 131 & $122(4.6)$ & 10.7 & 10.2 & 10.0 & 6.0 & 6.1 & 6.6 & 3.5 & 3.8 & 61 & 58 & 2.6 & 2.2 \\
\hline Standard dev. indiv. diff. & & & & $13(1.7)$ & & 0.7 & 0.6 & & 0.8 & 0.6 & & 0.4 & & 7 & & 0.3 \\
\hline 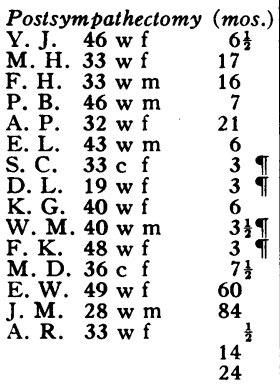 & $\begin{array}{l}\text { I } \\
\text { II } \\
\text { II } \\
\text { II } \\
\text { I } \\
\text { II } \\
\text { III } \\
\text { II } \\
\text { II } \\
\text { II } \\
\text { IV } \\
\text { II } \\
\text { II } \\
\text { IV } \\
\text { II } \\
\mathbf{0} \\
\mathbf{0}\end{array}$ & $\begin{array}{l}123 \\
135(9.1) \\
114 \\
104(5.9) \\
110(9.1) \\
159(8.1) \\
168(7.5) \\
125(9.9) \\
133(4.9) \\
92(7.8) \\
101(7.1) \\
162(8.5) \\
146(5.5) \\
163(7.7) \\
108 \\
94 \\
95\end{array}$ & $\begin{array}{r}104 \\
92 \\
98 \\
115 \\
141 \\
151 \\
79 \\
120 \\
83 \\
100 \\
135 \\
127 \\
153 \\
\\
77 \\
77\end{array}$ & $\begin{array}{c}92 \\
49(6.0) \\
91 \\
98 \\
102 \\
127(7.4) \\
133(8.8) \\
63(8.8) \\
110(4.6) \\
83(7.4) \\
60(6.8) \\
101(7.7) \\
116(3.3) \\
150(7.5) \\
77 \\
70 \\
59\end{array}$ & $\begin{array}{r}10.9 \\
10.4 \\
12.1 \\
10.7 \\
8.3 \\
10.4 \\
8.5 \\
10.9 \\
10.4 \\
12.4 \\
9.1 \\
12.3 \\
10.5 \\
10.7 \\
8.4 \\
8.7 \\
9.2\end{array}$ & $\begin{array}{r}9.9 \\
9.8 \\
11.9 \\
10.7 \\
9.0 \\
11.1 \\
8.9 \\
9.7 \\
9.5 \\
11.2 \\
9.6 \\
10.9 \\
8.2 \\
10.2 \\
7.4 \\
7.6\end{array}$ & $\begin{array}{r}9.6 \\
6.6 \\
11.4 \\
10.1 \\
7.9 \\
10.6 \\
8.4 \\
9.8 \\
9.6 \\
11.2 \\
8.6 \\
10.5 \\
7.6 \\
11.9 \\
8.7 \\
7.8 \\
7.7\end{array}$ & $\begin{array}{l}4.7 \\
6.9 \\
5.3 \\
6.3 \\
8.0 \\
6.3 \\
8.6 \\
4.5 \\
5.1 \\
5.2 \\
6.4 \\
6.6 \\
7.1 \\
6.7 \\
6.9 \\
6.1 \\
6.0\end{array}$ & $\begin{array}{l}6.5 \\
6.5 \\
6.2 \\
6.8 \\
6.9 \\
8.5 \\
7.5 \\
5.9 \\
5.5 \\
6.4 \\
5.5 \\
7.2 \\
8.8 \\
8.6 \\
8.0 \\
7.2\end{array}$ & $\begin{array}{r}6.5 \\
11.2 \\
6.5 \\
7.0 \\
8.0 \\
6.3 \\
8.3 \\
5.9 \\
6.1 \\
7.0 \\
6.9 \\
8.1 \\
10.1 \\
7.3 \\
6.6 \\
7.6 \\
7.3\end{array}$ & $\begin{array}{l}3.4 \\
5.3 \\
3.3 \\
3.3 \\
3.7 \\
2.5 \\
3.4 \\
2.3 \\
4.2 \\
3.8 \\
4.3 \\
3.4 \\
2.7 \\
5.4 \\
3.5 \\
3.9 \\
3.2\end{array}$ & $\begin{array}{l}4.0 \\
5.0 \\
3.3 \\
4.1 \\
3.6 \\
2.8 \\
3.8 \\
4.1 \\
4.3 \\
3.9 \\
4.8 \\
3.6 \\
3.2 \\
4.2 \\
3.0 \\
3.9 \\
3.9\end{array}$ & $\begin{array}{l}72 \\
77 \\
62 \\
52 \\
46 \\
40 \\
39 \\
50 \\
82 \\
73 \\
67 \\
51 \\
38 \\
81 \\
51 \\
64 \\
53\end{array}$ & $\begin{array}{l}62 \\
44 \\
51 \\
59 \\
45 \\
45 \\
46 \\
69 \\
71 \\
55 \\
69 \\
44 \\
32 \\
57 \\
45 \\
52 \\
53\end{array}$ & $\begin{array}{l}1.7 \\
1.8 \\
1.8 \\
2.0 \\
2.4 \\
4.0 \\
4.3 \\
2.5 \\
1.6 \\
1.3 \\
1.5 \\
3.2 \\
3.8 \\
2.0 \\
2.1 \\
1.5 \\
1.8\end{array}$ & $\begin{array}{l}1.5 \\
1.1 \\
1.8 \\
1.7 \\
2.3 \\
2.8 \\
2.9 \\
0.9 \\
1.5 \\
1.5 \\
0.9 \\
2.3 \\
3.6 \\
2.6 \\
1.7 \\
1.3 \\
1.1\end{array}$ \\
\hline Mean & & $125(7.6)$ & 110 & $93(6.6)$ & 10.2 & 9.7 & 9.3 & 6.3 & 7.0 & 7.5 & 3.6 & 3.9 & 59 & 53 & 2.3 & 1.9 \\
\hline Standard dev. indiv. diff. & & & & $21(1.1)$ & & 0.9 & 1.2 & & 1.0 & 1.2 & & 0.6 & & 13 & & 0.6 \\
\hline $\begin{array}{l}\text { Normotensive patients } \\
\text { previously reported (1) } \\
\text { Mean }\end{array}$ & & 88 & & 73 & 10.3 & & 10.4 & 6.1 & & 6.3 & 3.2 & 3.3 & 53 & 54 & 1.7 & 1.4 \\
\hline Standard dev. indiv. diff. & & & & 7 & & & 0.9 & & & 0.6 & & 0.3 & & 5 & & 0.2 \\
\hline
\end{tabular}

* $\mathrm{S}$ signifies supine position mean values.

$3^{\prime}$ signifies mean values after patients had been three minutes in the $20^{\circ}$ head-up position.

$20^{\prime}$ signifies mean values af ter patients had been 20 minutes in the $20^{\circ}$ head-up position.

† Signifies "effective" cerebral mean arterial pressure divided by cerebral blood flow.

$\ddagger$ Signifies patients studied after sympathectomy.

\$ Signifies jugular venous pressure that was subtracted from calculated cerebral pressure to give "effective" pressure.

Signifies patient had symptoms after 12 minutes head-up requiring return to supine position.

Tी Signifies patient had entire right adrenal removed at time of second stage sympathectomy. 
TABLE II

- Comparison of the per cent changes in cerebral circulation and oxygen metabolism with $20^{\circ}$ tilt

\begin{tabular}{l|c|c|c|c|c|c}
\hline \hline \multicolumn{1}{c|}{ Patient group } & \multicolumn{3}{|c}{ Cerebral } \\
\cline { 2 - 6 } & $\begin{array}{c}\text { “Effective" mean } \\
\text { arterial pressure }\end{array}$ & $\begin{array}{c}\text { Jugular oxygen } \\
\text { content }\end{array}$ & Blood flow & $\begin{array}{c}\text { Vascular } \\
\text { resistance }\end{array}$ & Oxygen uptake & $\begin{array}{c}\text { A-V O, } \\
\text { difference }\end{array}$ \\
\hline $\begin{array}{c}\text { Essential hypertension, } 18 \\
\text { pts., } 18 \text { observ'ns }\end{array}$ & $-16^{*}$ & $-6^{*}$ & -5 & $-15^{*}$ & $+9^{*}$ & $+10^{*}$ \\
\hline $\begin{array}{l}\text { Postsympathectomy, 15 } \\
\text { pts., 17 observ'ns }\end{array}$ & $-26^{*}$ & $-9^{*}$ & -11 & $-17^{*}$ & +8 & $+19^{*}$ \\
\hline $\begin{array}{l}\text { Normotensive, 5 pts., } 5 \text { ob- } \\
\text { serv'ns. Prev. reported } \\
\text { (1) }\end{array}$ & $-17^{*}$ & +1 & +2 & -18 & +3 & +3 \\
\hline
\end{tabular}

* Signifies statistically significant differences from the mean values in the supine position $(p<0.01)$.

sure. The $26 \%$ reduction was identical with that of the entire postsympathectomy group.

\section{Cerebral venous blood oxygen content and brain blood flow}

In both groups of patients the internal jugular blood oxygen concentration was reduced significantly from the recumbent value $(p<0.01)$. Comparable increases in the cerebral arteriovenous oxygen differences were observed. The increase in this oxygen difference after three minutes of tilt was significant in the patients studied after sympathectomy $(p<0.02)$, but was not in the patients with essential hypertension. The decreases in the oxygen content of cerebral venous blood after 20 minutes of tilt cannot be attributed to significant reductions in cerebral blood flow in either group (Table II).

\section{Cerebral oxygen consumption}

Although the cerebral arteriovenous oxygen difference increased only $10 \%$ in the hypertensives, the $9 \%$ increase in cerebral oxygen consumption after 20 minutes of tilt proved to be highly significant $(p<0.01)$. Cerebral oxygen consumption was not increased in the postsympathectomy group.

\section{Cerebrovascular resistance}

The cerebral blood flow of the patients after sympathectomy was decreased $11 \%$ with a $26 \%$ reduction in "effective" mean cerebral pressure. This can be explained by the fact that the cerebrovascular resistance decreased $17 \%$ from 2.3 to 1.9 units, indicating a highly significant relaxation of cerebral vessels during the tilt period. A comparable reduction in cerebrovascular resistance was found both in the hypertensive patients and in the normotensive subjects (1).

\section{Untoward symptoms during tilt}

It is noteworthy that no symptoms suggesting an inadequate cerebral circulation were encountered while the surgically treated patients were tilted. However, three patients with essential hypertension, L. B., R. A., and W. B. (Table I), having been immobile at least 12 minutes in the tilt position, suddenly developed sweating, nausea, weakness, bradycardia, marked drop in blood pressure and syncope. These were ameliorated by a return to the horizontal and the 20 minute observations in these patients were made there. $R$. A. and W. B. had reductions in pressure considerably greater than the mean of the group, indicating that the pressure had not returned to the pretilt level over a 15 minute period following the fainting episode. The other patient, L. B., had a $25 \%$ fall in blood flow (91 to 68) even though the pressure rose toward the control observation. There was an increase in resistance in this patient, without an appreciable increase in the cerebral arteriovenous oxygen difference. Each of these patients showed a decrease of 0.6 vol. \% or more in the oxygen content of the internal jugular blood when compared with the pretilt concentration. It is of interest that L. B. had a transient left hemiplegia one month before. Some slight weakness of the left leg was present at the time of this study. The supine cerebral blood flow, cerebral arteriovenous oxygen difference, cerebral oxygen uptake, and 
cerebrovascular resistance were not characteristic of essential hypertension (5).

\section{Tilt studies before and at intervals after sym- pathectomy in the same patient}

Postural hypotension of a moderate degree was observed with the tilt test over the two year period following sympathectomy in patient A. R. (Table I). Although this patient had only moderate hypertension preoperatively, she was troubled with severe headaches and had evidence of vascular damage of such a degree as to warrant sympathectomy. Following operation, she had complete relief from headache. The fundi are now normal. The heart size and electrocardiogram are now normal. Renal dysfunction has not progressed.

Tilt tests were made before operation, two weeks, 14 months, and two years after sympathectomy. The cerebral blood flow during the most recent tilt study was unchanged when the "effective" mean cerebral pressure was reduced $38 \%$. These measurements indicate that the cerebral vessels in this patient are capable of considerable relaxation at this time, cerebrovascular resistance having decreased equally with the arterial pressure. There was, however, a $25 \%$ increase in cerebral arteriovenous oxygen difference and oxygen consumption as jugular blood oxygen content decreased 1.5 vol. \% when compared with the supine observation. No unpleasant symptoms were observed during this tilt period. Two other patients were studied before as well as after sympathectomy (D. L. and W. M., Table I). Cerebral blood flow increased with tilt in one, but decreased in the other. Both of these patients have had a good clinical response for at least one year after operation.

\section{COMMENT}

These studies offer additional evidence that the high tone of cerebral vessels normally present in essential hypertension is capable of partial relaxation in response to a fall in cerebral arterial pressure induced by $20^{\circ}$ tilt for 20 minutes. A comparable degree of relaxation, tending to counteract the decrease in cerebral blood flow which would otherwise occur, has been found in the group tilted after sympathectomy. The decrease in the resist- ance in the latter group during tilt appeared to augment the previously mentioned reduction in cerebrovascular resistance in the supine position after sympathectomy (2). Although the cerebral oxygen uptake of the sympathectomy group was unchanged by the $20^{\circ}$ head-up position, there was a highly significant reduction in the oxygen content of the jugular blood in both groups. Kety and associates have observed a similar trend in a study of the cerebral circulatory response to the acute reduction in cerebral mean arterial pressure induced by differential spinal anesthesia (7). We interpret this as an indication that the increased tone of the cerebral vessels usually present in essential hypertension and persisting after sympathectomy could only be partly relaxed in response to the fall in pressure induced by this slight degree of tilt.

The cerebral arteriovenous oxygen difference was not increased by tilt as much in the patients with essential hypertension as in the patients tested after sympathectomy (Table II). Cerebral blood flow was reduced about the same amount. However, the $9 \%$ increase in cerebral oxygen uptake was highly significant $(p<0.01)$. This was not observed in the normotensive group. The measurements of this study offer us no explanation.

The symptoms experienced by hypertensive patients during tilt were similar to those observed during a sudden fall in arterial pressure from differential spinal sympathetic block (7). These data are further evidence suggesting that such symptoms were the result of cerebral anoxia associated with an inadequate circulation while in this position. A decrease in cerebral blood flow and an increase in the cerebral arteriovenous oxygen difference have been reported when normotensive subjects were tilted to a $65^{\circ}$ head-up position and held there for ten minutes (6).

Our data give us no ready explanation for the difference in the symptomatic response of the two hypertensive groups to this slight degree of headup tilt. It is probable that the absence of collapse symptoms in the postsympathectomy group was fortuitous.

The patient E. L. (Table I) was studied six months after sympathectomy. He had suffered a right hemiplegia one week after the second stage was completed. Although this patient had complete motor and sensory recovery within the next 
week, some weakness of the right leg remained at the time of this tilt study. E. L. had been studied before operation and there appeared to be no essential difference in the supine data, published as part of a report of the effect of stellate block (8). However, the $16 \%$ increase in blood flow during tilt with no decrease in cerebral arteriovenous difference raised the question of shunts through damaged cerebral tissue. Also of interest is the fact that the patient suffered a right homonymous hemianopia six weeks after the tilt study. This gradually cleared within three months.

Kety (9) and Schmidt (10) (Table II) have recently summarized the evidence from investigations over the past four years bearing on the relationship between arterial hypertension and the marked increase in cerebral vascular resistance accompanying it. They suggest a humoral agent as the mediator of the increased cerebral vascular resistance as well as the uniform increase in vascular tone throughout the body. The results of the present study in which hypotension was induced in the cerebral arterial system under slight physiologic stress also show that the increased cerebral vascular resistance can be decreased when the "effective" arterial pressure is lowered. The failure of the cerebral vasculature to relax to the degree enabling the oxygen content of the internal jugular vein blood to remain unchanged might be considered as further evidence suggesting the presence of a circulating pressor substance.

That relaxation of the tone of cerebral blood vessels is possible in hypertension has been demonstrated by studies of the cerebral circulation after sympathectomy (2) and following intramuscular dihydroergocornine (11). Following the administration of this drug cerebral blood flow, cerebral arteriovenous oxygen difference, and oxygen content of the internal jugular vein were essentially unchanged when the arterial pressure was significantly reduced. These latter observations seem to answer in the affirmative the question: Can the elevated arterial pressure of patients with essential hypertension be lowered without untoward symptoms that might be related to a decrease in cerebral blood flow, cerebral oxygen up. take, and mean cerebral oxygen tension? ${ }^{\circ}$

${ }^{6}$ The authors recognize that venous oxygen content is a less adequate measure of cerebral oxygen homeostasis than venous oxygen saturation or tension (7).

\section{SUM MARY}

Measurements of cerebral blood flow, cerebral oxygen uptake and cerebral vascular resistance were made by the nitrous oxide method before and after $20^{\circ}$ head-up tilt in patients with essential hypertension. A significant reduction in "effective" cerebral arterial pressure during the tilt was observed.

Cerebral blood flow was not reduced significantly during tilt in either group. Cerebral vascular resistance was reduced in both. Oxygen uptake of the brain increased when the patients with essential hypertension were tilted and was unchanged in the sympathectomy group. Symptoms of cerebral anoxia were not observed in these patients.

The oxygen content of the blood from the internal jugular vein in the two groups of patients was significantly reduced while semi-erect. This indicates that, although the cerebral vascular resistance was diminished, the increased tone was only partially relaxed.

From the data obtained we believe the following conclusions may be drawn:

1. The increased cerebral vascular resistance in essential hypertension can be partially relaxed when the arterial pressure is lowered by this slight degree of tilt.

2. Patients studied after sympathectomy showed the same degree of incomplete relaxation with tilt as the patients with essential hypertension, but did not experience cerebral anoxia.

3. Failure of the cerebral vasculature to relax completely might be considered as evidence suggesting the presence of significant amounts of circulating pressor substances even in the patients who have had a sympathectomy.

\section{REFERENCES}

1. Shenkin, H. A., Scheuerman, W. G., Spitz, E. B., and Groff, R. A., The effects of change of position upon the cerebral circulation of man. Am. J. M. Sc., 1948, 216, 714.

2. Shenkin, H. A., Hafkenschiel, J. H., and Kety, S. S., Effects of sympathectomy on the cerebral circulation of hypertensive patients. Arch. Surg., 1950, 61, 319.

3. Wagener, H. P., and Keith, N. M., Diffuse arteriolar disease with hypertension and the associated retinal lesions. Medicine, 1939, 18, 317. 
4. Kety, S. S., and Schmidt, C. F., The nitrous oxide method for the quantitative determination of cerebral blood flow in man: theory, procedure and normal values. J. Clin. Invest., 1948, $27,476$.

5. Kety, S. S., Hafkenschiel, J. H., Jeffers, W. A., Leopold, I. H., and Shenkin, H. A., The blood flow, vascular resistance and oxygen consumption of the brain in essential hypertension. J. Clin. Invest., 1948, $27,511$.

6. Scheinberg, P., and Stead, E. A., Jr., The cerebral blood flow in male subjects as measured by the nitrous oxide technique. Normal values for blood flow, oxygen utilization, glucose utilization and peripheral resistance, with observations on the effect of tilting and anxiety. J. Clin. Invest., 1949, 28, 1163.

7. Kety, S. S., King, B. D., Horvath, S. M., Jeffers, W. A., and Hafkenschiel, J. H., The effects of an acute reduction in blood pressure by means of differential spinal sympathetic block on the cerebral circulation of hypertensive patients. J. Clin. Invest., 1950, 29, 402.

8. Harmel, M. H., Hafkenschiel, J. H., Austin, G. M, Crumpton, C. W., and Kety, S. S., The effect of bilateral stellate ganglion block on the cerebral circulation in normotensive and hypertensive patients. J. Clin. Invest., 1949, 28, 415.

9. Kety, S. S., Circulation and metabolism of the human brain in health and disease. Am. J. Med., 1950, 8, 205.

10. Schmidt, C. F., The Cerebral Circulation in Health and Disease. Charles C. Thomas, Springfield, IIl., 1950, Ed. 1, p. 67.

11. Hafkenschiel, J. H., Crumpton, C. W., Moyer, J. H., and Jeffers, W. A., The effects of dihydroergocornine on the cerebral circulation of patients with essential hypertension. J. Clin. Invest., 1950, 29, 408.

\section{ERRATUM}

In the article entitled "The Measurement of C-reactive Protein in Human Sera. Comparison of the Clinical Tests on the Basis of a Quantitative Method," by Harrison F. Wood and Maclyn McCarty, in the June 1951 issue (pp. 616-622), the data giving the concentration of $\mathrm{C}$-reactive protein in human sera were calculated without allowance for the twofold concentration employed in the final step of the quantitative method. Consequently, the values for the concentration of the protein in human sera found in Table IV and in the text should be divided by two to obtain the correct figures. 